\title{
Reduction of negative impact on the geoenvironment using silica sol in road construction
}

\author{
Antonina Sakharova ${ }^{1, *}$, Ivan Kozlov ${ }^{1}$, Marina Baydarashvili ${ }^{1}$, and Andrei Petriaev ${ }^{1}$ \\ ${ }^{1}$ Emperor Alexander I St. Petersburg State Transport University, 9 Moskovsky pr., St.Petersburg, \\ 190031, Russia
}

\begin{abstract}
Consumption and pollution of natural resources must be constantly compensated by their conservation, saving and restoration to create a balance in the ecosystem between man and nature. To solve this problem any construction process must be accompanied by geoecoprotective measures. The authors of the article suggest to use silica sol in the soils stabilization and reinforcement technology. Silica sol is a pure mineral product that has binding properties and neutralizing properties against some pollutants. This makes it suitable for soils reinforcement and also soils neutralization from pollutants such as heavy metals ions. The stabilization technology using technogenic soils and silica sol will conserve natural resources, improves the soil strength properties and neutralize them from pollutants.
\end{abstract}

\section{Introduction}

The main problems in the relationship between man and nature are the need to save natural resources and preserve the productive environment for future generations. The sustainable development concept of society is based on these principles [1].

Quite a lot of ideas and methods that can solve these problems developed by the scientists of the Engineering Chemistry and Natural Sciences Department of Emperor Alexander I St. Petersburg State Transport University [2-7] and by other researches [8-10]. However for their implementation is necessary to search the construction technologies in which it would be possibly and expediently to apply these scientific developments.

Soling is one of the most progressive and innovative developments. Its meaning is the use of sols of mineral nature as inorganic binders which can be used, for example, for soils reinforcement with the simultaneous neutralization of some pollutants. Studies have shown that silica sol has neutralizing properties in relation to such pollutants as heavy metal ions transforming them in low-solubility compounds [11-13]:

$$
\mathrm{Me}^{2+}+\mathrm{SiO}_{2} \cdot \mathrm{H}_{2} \mathrm{O}+4 \mathrm{OH}^{-}=\mathrm{Me}(\mathrm{OH})_{2} \downarrow+\mathrm{MeO} \cdot \mathrm{SiO}_{2} \cdot \mathrm{H}_{2} \mathrm{O}+\mathrm{H}_{2} \mathrm{O}
$$

This mechanism of silica sol strengthening effect is analogous well-known mechanism of liquid glass use for soils reinforcement:

\footnotetext{
*Corresponding author: assakharova@list.ru
} 


$$
\begin{array}{r}
\mathrm{Na}_{2} \mathrm{SiO}_{3}+2 \mathrm{H}_{2} \mathrm{O}=2 \mathrm{NaOH}+\mathrm{SiO}_{2} \cdot \mathrm{H}_{2} \mathrm{O} \\
\text { silica gel }
\end{array}
$$

Unlike reaction (2), silica gel obtained by silicification (reaction (1)) is a pure product that does not alkalize the construction system by alkali hydroxide $\mathrm{NaOH}$ and does not the lithosphere like reaction (2). This is the principal geoecological advantage of silica gel. This is a pure mineral product derived from silica sol which has neutralizing and binding properties.

An aqueous solution of the sol which contains nanosize particles $(1 \ldots 10 \mathrm{~nm})$ is used in the soling technology. Firstly these particles are able to transform into a gel (their binding property is manifested in this state), and secondly to interact spontaneously with substances in processes occurring with a decrease of the free Gibbs energy. It can be the neutralization processes.

According to the authors of the article, there is a correlation between constructive, technical and geoecoprotective properties, which should be taken into account in modern progressive technologies. Because issues of ecology and geoecology become vitally important for people and the Earth.

\section{Soils Stabilization And Reinforcement Methods}

In the continuation of the studies [10-13] it was proposed in this article to use silica sol in the soils stabilization and reinforcement technology for their purification from heavy metals ions pollution. Binder and very wet soils are not suitable for compaction by compactors. In such cases the local soil should first be stabilized to increase its bearing capacity and prepare it as a basis for road surface paving [12-14]. Stabilization provides reliable binding of water in the soil. It is carried out by injecting lime or cement into the soil (figure 1).

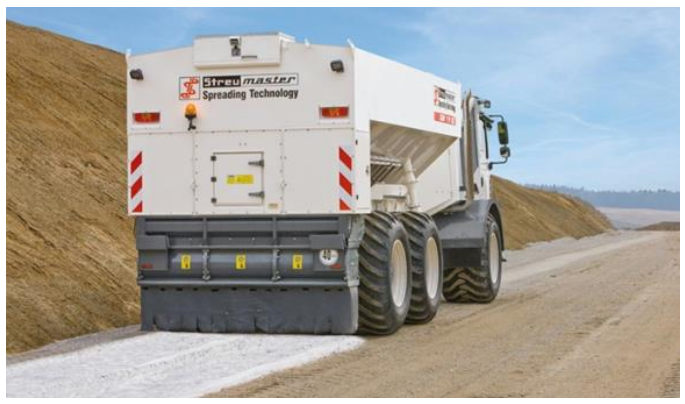

Fig. 1. Binder application on the soil.

The base becomes more resistant to transport loads, water penetration and frost for a long time. The stabilization method by using cement characterizes these features.

The soil, which requires stabilization, is often marshy and only powerful vehicles with four-wheel drive can move through its. For this reason machines for soil stabilization have large studded tires, high throughput and a powerful running gear. Their milling and mixing chambers mix the previously applied binder with the soil (Figure 2). This reduces the water content in the soil and makes it loose and ideally suited for subsequent compaction by vibratory compactors (Figure 3).

Soil stabilization is an effective technology for creating a rigid and quality base for roads or areas. The use of inorganic binders, unique stabilizers and high-tech equipment can significantly reduce the time and cost of work. The soil stabilization technology transforms almost any soil into a solid base. 


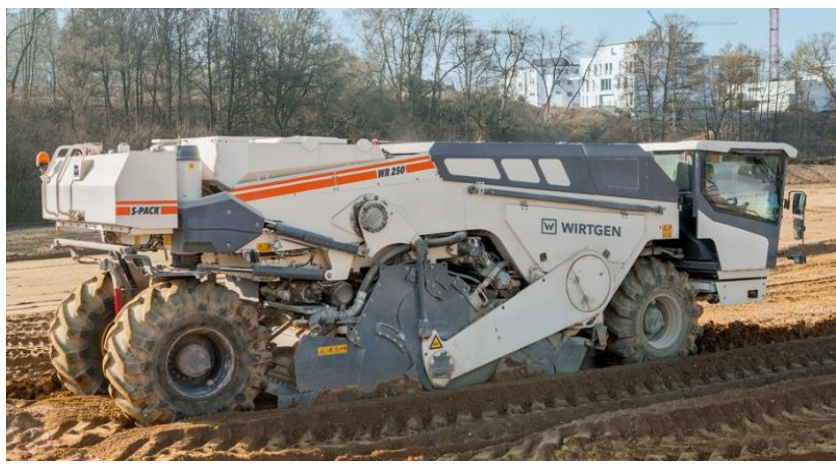

Fig. 2. Soil milling and mixing.

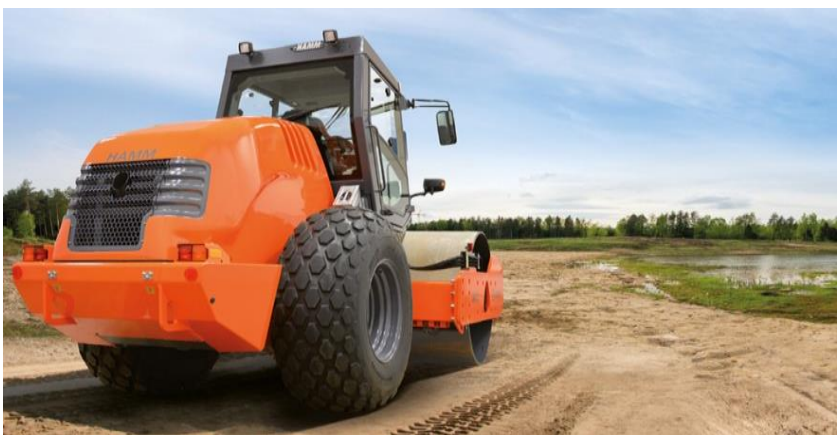

Fig. 3. Soil compaction.

Soil stabilization is the process of thorough crushing and mixing of soil with the corresponding inorganic binding materials. They are added in a proportion of $5-10 \%$ by weight and then compacted.

There is no need for a significant amount of transport when using this technology with inorganic binders. Because you can reinforce absolutely any local soil, for example loam, sandy loam or sandy soils, which are nearby. Only binder materials must be delivered to the work site.

It should be noted that the use of local soil is very important in terms of geoecology, since there is an economy of natural resources (soil imported).

In comparison with the traditional technology there is a $20 \mathrm{~cm}$ crushed stone and $30 \mathrm{~cm}$ sand saved. Also with the same strength characteristics the thickness of the asphalt concrete layer decreases from $10-12 \mathrm{~cm}$ to $4-6 \mathrm{~cm}$.

Soil stabilization technology is used in the construction of the following facilities:

- existing highways repair and reconstruction;

- roads IV-V category;

- temporary, technological, auxiliary and dirt roads;

- sidewalks, park, pedestrian and bicycle paths;

- parking lots, warehouses and shopping centers and terminals when creating solid bases for the construction of various categories objects;

- municipal solid waste and hazardous substances landfills;

- bases device under industrial floors and tiles paving;

- bases under railway tracks.

This method has the following advantages over the traditional methods of construction of road bases:

- reduction of the cost of construction works by $50 \%$; 
- increase the speed of work from $3000 \mathrm{~m} 2$ to $8000 \mathrm{~m} 2$ per shift;

- the compressive strength at stabilization of soil with the use of inorganic binders reaches $500 \mathrm{MPa}$;

- the warranty period of the road foundation with soil stabilization technology reaches 15 years.

- the presented advantages became possible due to the following factors:

- full refusal to use non-metallic materials (crushed stone, sand);

- lack of excavation work for the road construction and thus the lack of soil utilization;

- full mechanization of the process;

- the use of modern technology, which allows to accelerate the speed of work.

In Figure 4 shows the scheme of the main technological operations for the soils stabilization.

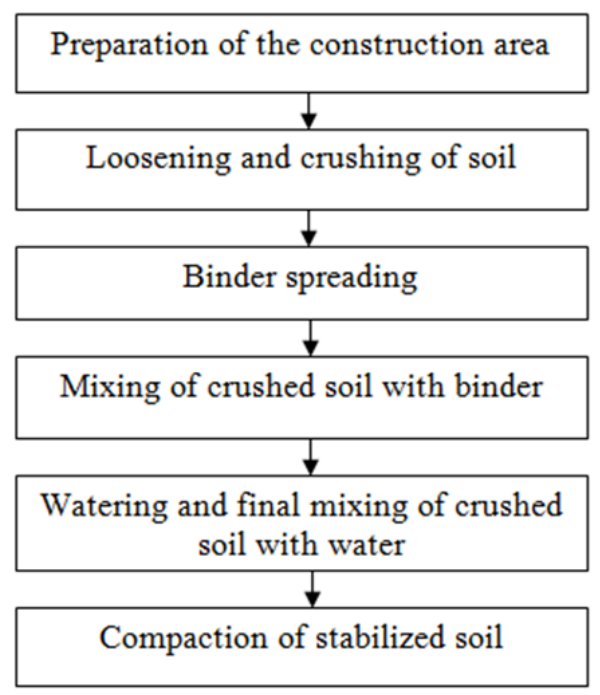

Fig. 4. Scheme of the main technological operations for soils stabilization.

Another important factor is that this method does not have harmful impact on the environment and involves complete freedom in the choice of material. Modern equipment can effectively stabilize the soil on site to a depth of $50-56 \mathrm{~cm}$ in one operation with high precision dosage of binders.

Soil stabilization allows to make the road efficiently and economically. Soils stabilization and reinforcement technology allows to achieve a reinforced base of the road, which is as strong as the asphalt-concrete cover.

The cost of bases and coatings construction from stabilized soil is 3.5-5 times cheaper than the construction of crushed stone bases or asphalt concrete pavements. The base layer of a stabilized soil $30 \mathrm{~cm}$ thickness is equal in strength to a layer of crushed stone $18-20 \mathrm{~cm}$ thickness; light coating of stabilized soil $15-20 \mathrm{~cm}$ thickness is equal to the strength of asphalt-concrete coating 6-10 $\mathrm{cm}$ thickness.

For best results we recommend the use of special additives. The soil reinforcement properties are improved significantly after addition of these additives in the soil together with cement or lime.

Analysis of the technique used in the technological processes implemented to stabilize and reinforce the soils, shows the possibility of adding silica sol to the soil instead of or together with water. Then the scheme of technological operations will be the following (Figure 5): 


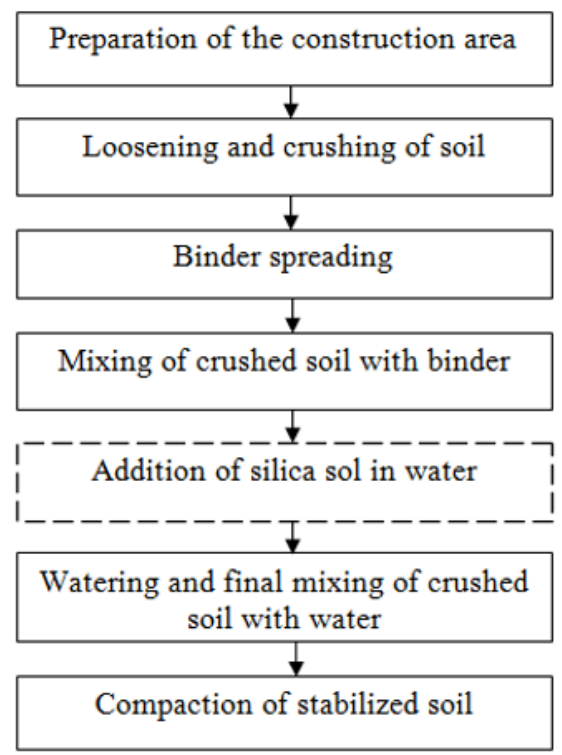

Fig. 5. Scheme of technological operations for soils stabilization with geoecoprotective function.

This solution binds up soil particles due to its unique characteristics and reinforces soil.

Application of silica sol together with additives (cement, lime or production waste) allow to reduce the amount of binder added into the soil, to increase cold resistance and crack resistance of reinforced soils. All these measures reduce the estimated cost of road construction.

\section{Discussion}

Thus soils stabilization and reinforcement technology (Figure 4) has the following geoecological advantages:

- removal of unused soil is not required (construction without waste);

- the amount of imported material is significantly reduced, since the delivery of crushed stone and sand to the work site is not required as in the traditional construction method;

- delivery cost and environmental impact are reduced;

- secondary industrial products can be used as base material.

A significant advantage of the proposed technology is that the crushing and mixing of the local soil with the binder is carried out directly at the site of construction (on the road) with the simultaneous addition of a specially selected complex of substances. In the case of repair or reconstruction of roads, the surface of which has been contaminated during their operation, the added silica sol (Figure 5) spontaneously reacts with dangerous pollutants such as heavy metal ions [15]. Therefore, the stabilization technology acquires a geoecoprotective function, which works not only at the moment of addition the substance into the soil, but also during the operation of the new structure.

\section{Conclusions}

- The soil stabilization technology is a modern and progressive construction technology as it conserves natural resources and improves the soils strength properties. This technology acquires a new geoecoprotective function due to the silica sol use. 
- The silica sol use allows not only to reinforce, but also to neutralize the soils contaminated by heavy metals ions. It is important for productive environment conservation for future generations.

\section{References}

1. A.S. Sakharova, L.B. Svatovskaya, M.M. Baidarashvili, A.V. Petriaev, Procedia Engineering 143 (2016)

2. L. Svatovskaya, Chemical engineering and natural science basis for the creation of new eco- and geoprotective technologies (PSTU, St. Petersburg, 2010)

3. A.S. Sakharova, L.B. Svatovskaya, M.M. Baidarashvili, A.V. Petriaev, Proc. of the 14th Int. Conf. of Int. Association for Computer Methods and Recent Advances in Geomechanics (2014)

4. M.V. Shershneva, E.I. Makarova, N.N. Efimova, Procedia Engineering 189 (2017)

5. L.L. Maslennikova, M.S. Abu-Khasan, N.A. Babak, Procedia Engineering 189 (2017)

6. T.S. Titova, Vniizht bulletin (railway research institute bulletin) 5 (2005)

7. A.S. Sakharova, M.M. Baidarashvili, A.V. Petriaev, Procedia Engineering 189 (2017)

8. J. Wang, P. Zhang, L. Yang, T. Huang, Chinese Journal of Chemical Engineering 23(9) (2015)

9. M. Ahmaruzzaman, Advances in Colloid and Interface Science 166(1-2) (2011)

10. D. Tedoldi, G. Chebbo, D. Pierlot, P. Branchu, Y. Kovacs, M. Gromaire, Science of The Total Environment 579 (2017)

11. K. Malchevskaya, A. Sakharova, A. Kabanov, Procedia Engineering 189 (2017)

12. A. Sychova, A. Solomahin, A. Hitrov, Procedia Engineering 189 (2017)

13. M.V. Gravit, V.I. Gumenjuk, M.M. Sychov, O. Nedyshkin, Procedia Engineering 117 (2015)

14. T.I. Boykova, V.Y. Solovyova, D.V. Solovyov, Procedia Engineering 189 (2017)

15. M. Baydarashvili, N. Shrednik, A. Spasovskaia, Procedia Engineering 189 (2017) 